
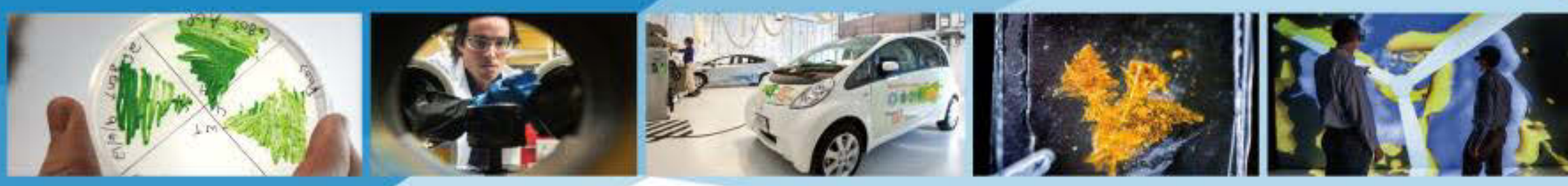

\title{
High-Efficiency Tandem Absorbers for Economical Solar Hydrogen Production
}

2017 U.S. DOE Hydrogen \& Fuel Cells Program Review

Todd G. Deutsch

June $8^{\text {th }}, 2017$

Project ID: PD115

This presentation does not contain any proprietary, confidential, or otherwise restricted information. 


\section{Overview}

\section{Timeline and Budget}

- Project start date: 10/1/14

- Project end date: 9/30/17

- Total project budget: $\$ 3 \mathrm{M}$

- Total recipient share: $\$ 0$

- Total federal share: $\$ 3 \mathrm{M}$

- Total DOE funds spent*: $\$ 2.5 \mathrm{M}^{* *}$

* As of $3 / 31 / 17$

** Includes UNLV, LLNL, LANL, UH support

\section{Barriers}

- Barriers addressed

- AE. Materials Efficiency-Bulk and interface

- AF. Materials Durability - Bulk and interface

- AG. Integrated Device Configurations

\section{Partners}

- Interactions/collaborations

- University of Nevada Las Vegas

- Lawrence Livermore National Lab

- University of Hawaii

- Stanford University

- University of Southern California

- JCAP-North

- University of Louisville

- University of Toledo

- Colorado School of Mines

- University of Colorado-Boulder

- Denmark Technical University 


\section{Relevance}

\section{Objectives}

- Long-Term: Develop highly-efficient, durable material that can operate under 10-15x (or higher) solar concentration and generate renewable hydrogen for $<\$ 2 / \mathrm{kg}$ from photoelectrochemical (PEC) water splitting

- Current year:

- Push boundaries on achievable semiconductor photoelectrochemical solar-to-hydrogen (STH) efficiencies

- Benchmarking: STH efficiencies for multijunction (tandem) PEC devices

- Continue development of stabilizing surface modifications viable at high current densities
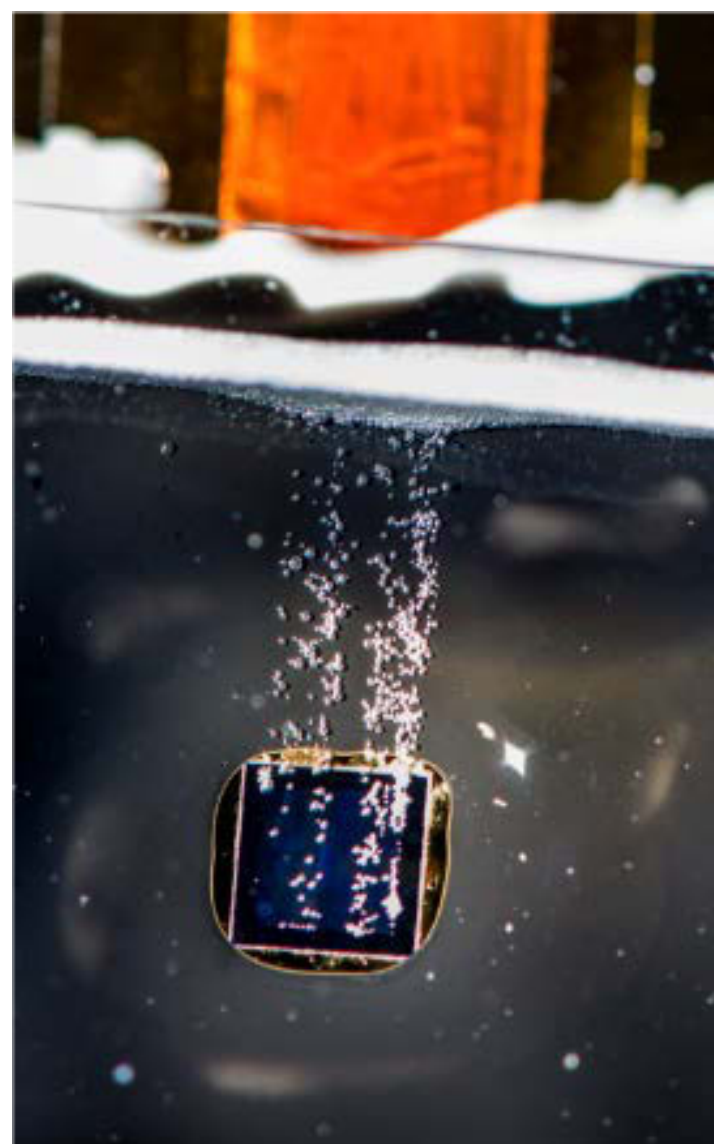


\section{Relevance}

DOE EERE Multi-Year Research, Development, and Demonstration Plan

Table 3.1.8 Technical Targets: Photoelectrochemical Hydrogen Production: Photoelectrode System with Solar Concentration "

\begin{tabular}{|c|c|c|c|c|c|}
\hline Characteristics & Units & $\begin{array}{c}2011 \\
\text { Status }\end{array}$ & $\begin{array}{c}2015 \\
\text { Target }\end{array}$ & $\begin{array}{c}2020 \\
\text { Target }\end{array}$ & $\begin{array}{l}\text { Ultimate } \\
\text { Target }\end{array}$ \\
\hline Photoelectrochemical Hydrogen Cost ${ }^{\mathrm{b}}$ & $\$ / \mathrm{kg}$ & NA & 17.30 & 5.70 & 2.10 \\
\hline $\begin{array}{l}\text { Capital cost of Concentrator \& PEC Receiver } \\
\text { (non-installed, no electrode) }\end{array}$ & $\$ / m^{2}$ & NA & 200 & 124 & 63 \\
\hline Annual Electrode Cost per TPD $\mathrm{H}_{2}{ }^{d}$ & $\begin{array}{c}\mathrm{S} / \\
\mathrm{yr}-\mathrm{TPDH}_{2}\end{array}$ & NA & $2.0 \mathrm{M}$ & $255 \mathrm{~K}$ & $14 K$ \\
\hline $\begin{array}{l}\text { Solar to Hydrogen (STH) Energy Conversion } \\
\text { Ratio }{ }^{a, t}\end{array}$ & $\%$ & 4 to $12 \%$ & 15 & 20 & 25 \\
\hline 1-Sun Hydrogen Production Rate & $\begin{array}{c}\mathrm{kg} / \mathrm{s} \text { per } \\
\mathrm{m}^{2}\end{array}$ & 3.3E-7 & $1.2 E-6$ & 1.6E-6 & $2.0 \mathrm{E}-6$ \\
\hline
\end{tabular}

Technoeconomic analysis for a type 4 (10x concentrator) PEC reactor

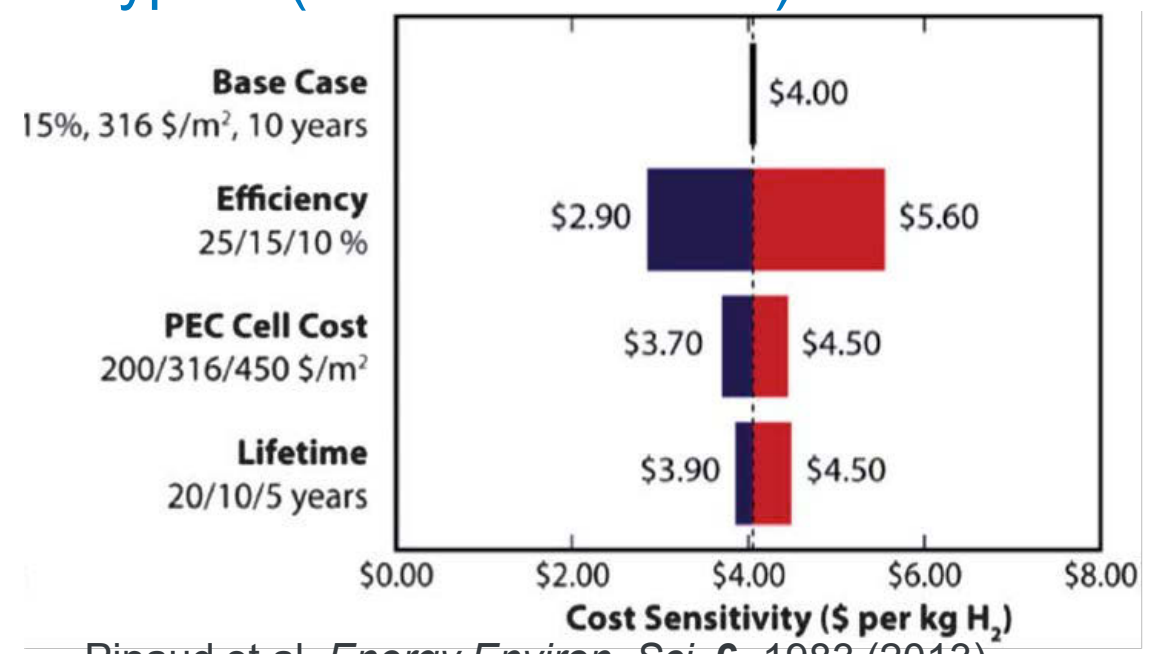

Pinaud et al. Energy Environ. Sci. 6, 1983 (2013)

\section{Project Guiding Principles}

- Primary focus is on efficiency, the largest lever to reduce $\mathrm{H}_{2}$ costs according to technoeconomic analysis

- Scalability is primary selection criterion, more important than earth abundance

- Durability is not an intractable issue

- Absorber cost can be addressed through engineering 


\section{Approach - Project Overview}

Maximize efficiency first then focus on durability via surface modifications, investigate lower-cost synthesis once material has been identified

- Tandem absorbers

- Task 1: Demonstrating attainable efficiencies

- III-Vs by MOCVD (NREL)

- Task 2: higher-risk, lowercost approaches

- $\ln _{\mathrm{x}} \mathrm{Ga}_{1-\mathrm{x}} \mathrm{N}$ tandems (LANL)

- III-V-N on Si tandems (NREL)

- Coupled photoanodephotocathode systems (Hawaii, NREL)

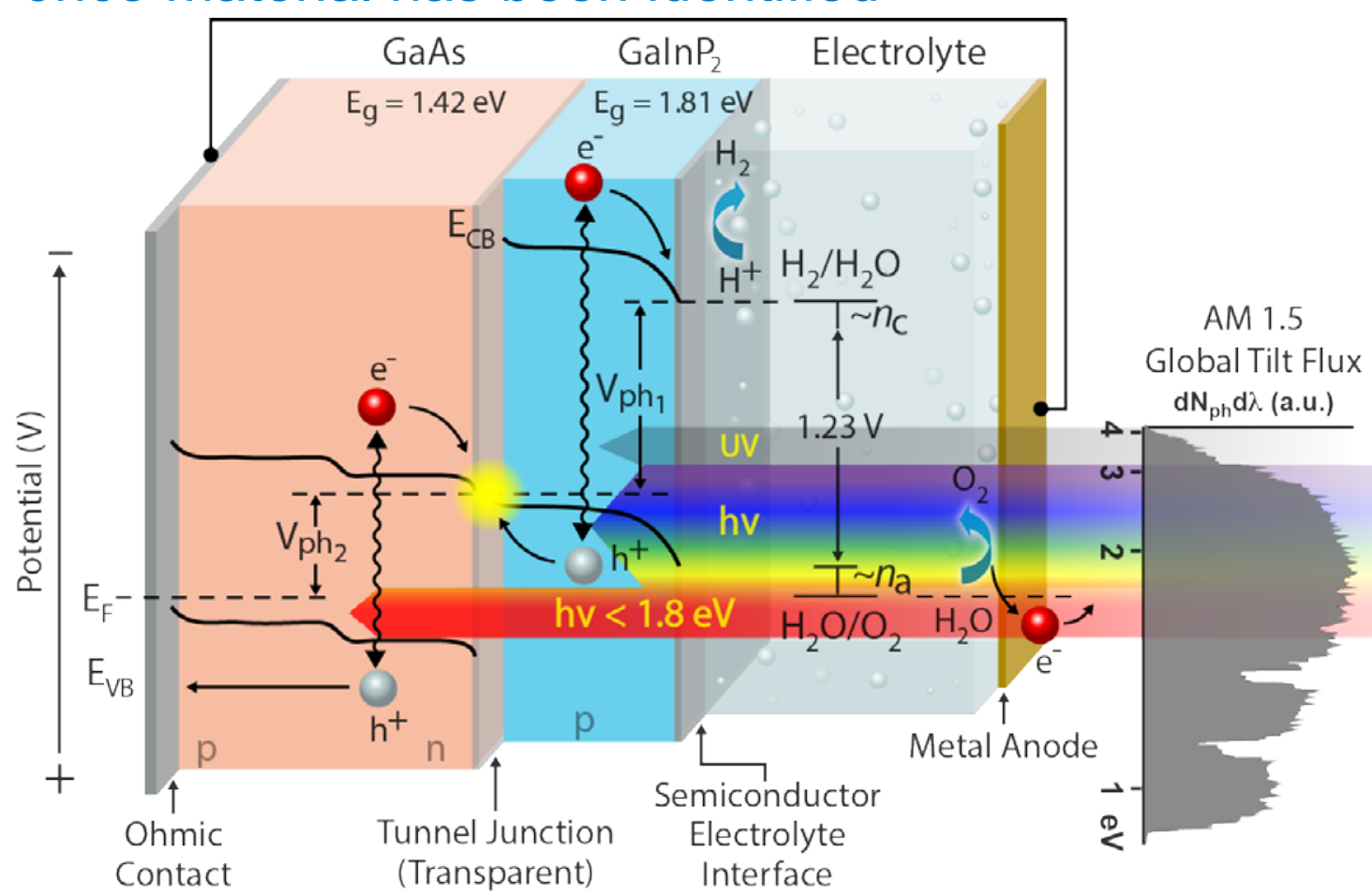

- Surface modifications - spectroscopy (UNLV) and modeling (LLNL)

- Ion-implantation \& flash sputtering (NREL)

- Thin coatings by atomic layer deposition (ALD) (NREL, CU)

- Molybdenum disulfide $\left(\mathrm{MoS}_{2}\right.$ ) coatings (Stanford)

- Benchmarking, prototyping, \& demonstration

- Photoreactor design and outdoor device testing (NREL, JCAP-Solar Fuel Hub) 


\section{Approach: Surface Validation Team}

Understanding and remedying semiconductor photocorrosion at PEC interfaces is a complex task that has benefitted significantly from a collaborative approach teaming experts with unique capabilities and resources

\section{- Heske group at UNLV}

- XPS, XAS, XES, IPES, UPS, AFM

- Some measurements at Advanced Light Source (ALS), Berkeley Lab

- Snapshots of surface pre-, intermediate, post-exposure

- Identify common features of and conditions that lead to corrosion

- Characterize stabilized surfaces

- Show where we are in parameter space wrt. amounts of $\mathrm{N} \& \mathrm{PtRu}$
- Ogitsu group at LLNL

- Develop theoretical tool chest for modeling PEC systems

- Simulate $x$-ray spectra to correlate UNLV experimental results with surface/near surface compositions

- Model III-V surfaces to uncover the key mechanisms of surface corrosion
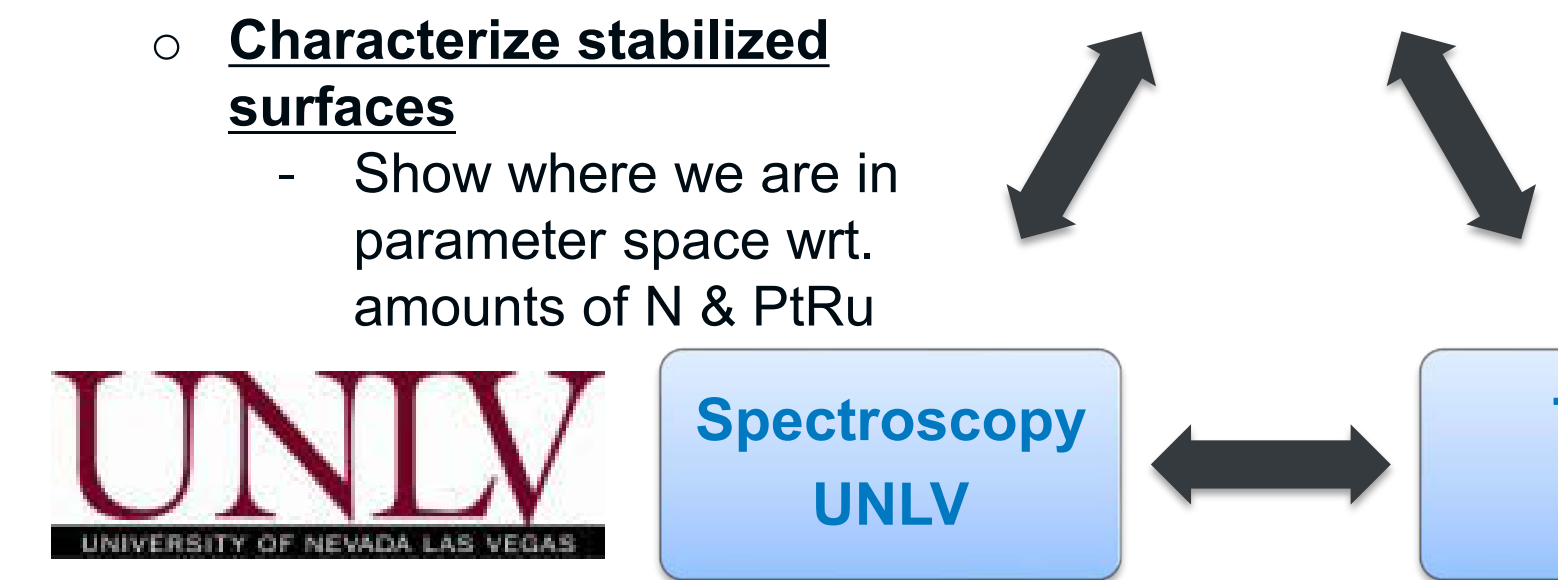

\section{NREL}

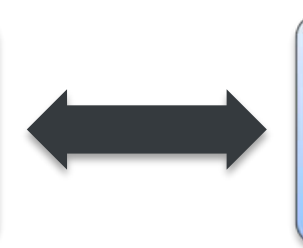

Theory LLNL

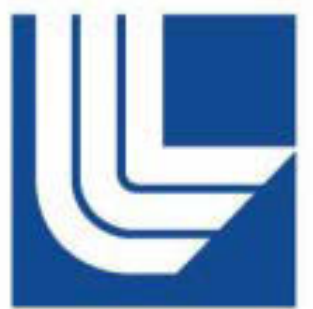




\section{Approach: Milestones}

\begin{tabular}{|c|c|c|c|c|}
\hline Qtr & Due & Туре & Millestones, Deliverables, or Go/No-Go Decision & Status \\
\hline FY16 & $6 / 30 / 16$ & Regular & $\begin{array}{l}\text { Validate Faradaic efficiency by measuring the } \mathrm{H}_{2} / \mathrm{O}_{2} \text { ratio in } \mathrm{PEC} \text { product gas stream } \\
\text { mixed with inert sweeping gas using a capillary mass-spectrometer }\end{array}$ & Complete \\
\hline $\begin{array}{l}\text { FY16 } \\
\text { Q4 }\end{array}$ & 9/30/16 & Annual & $\begin{array}{l}\text { Using two-terminal J-V, validate over } 15 \% \text { STH on a surface modified electrode prior } \\
\text { to durability testing. Durability testing will be performed potentiostatically or } \\
\text { galvanostatically where the photocurrent should be maintained above } 12 \mathrm{~mA} / \mathrm{cm}^{2} \text { for } \\
875 \text { continuous hours under } 1 \text {-sun illumination. Upon completion of durability testing, } \\
\text { use two-terminal J-V to demonstrate that the surface modified electrode has } \\
\text { experienced less than } 20 \% \text { loss in STH efficiency. }\end{array}$ & Complete \\
\hline \begin{tabular}{r|r|r|} 
FY17 \\
Q1
\end{tabular} & $12 / 31 / 16$ & Regular & $\begin{array}{l}\text { Demonstrate a lowered bottom bandgap tandem that uses a 1.1eV bottom cell to } \\
\text { achieve higher photocurrent densities under AM1.5 conditions. Determine if it } \\
\text { generates sufficient voltage, when combined with a } 1.7 \mathrm{eV} \text { top cell, to split water at } \\
\text { zero bias at higher efficiency than a } 1.2 / 1.8 \mathrm{eV} \text { bandgap combination. }\end{array}$ & Complete \\
\hline \begin{tabular}{c|} 
FY17 \\
Q2
\end{tabular} & $3 / 31 / 17$ & Regular & $\begin{array}{l}\text { Develop and test a tandem cell that uses a quaternary (GalnAsP) } 1.7 \text { eV bandgap } \\
\text { top cell and evaluate its durability at short circuit. Epilayer (non-tandem standalone } \\
\text { junctions) GalnAsP has demonstrated greater stability than } G a l n P_{2} \text {, but true } \\
\text { durability evaluation requires a tandem that can operate without an external bias. }\end{array}$ & Complete \\
\hline \begin{tabular}{r|r} 
FY17 \\
Q3
\end{tabular} & $6 / 30 / 17$ & Regular & $\begin{array}{l}\text { Develop an epitaxial capping layer that exhibits at least } 100 \text { hours of durability when } \\
\text { tested on a tandem cell immersed in electrolyte operating at short circuit. }\end{array}$ & On-track \\
\hline 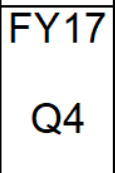 & $9 / 30 / 17$ & Annual & $\begin{array}{l}\text { Incorporate most efficient and stable material in a photoreactor on a tracker and } \\
\text { demonstrate } 8 \text { hours of continuous operation in sunlight with a cumulative production } \\
\text { of at least } 3 \text { standard liters of } \mathrm{H}_{2} \text {. }\end{array}$ & On-track \\
\hline
\end{tabular}

\section{All program milestones are completed or on-track for on-time completion.}




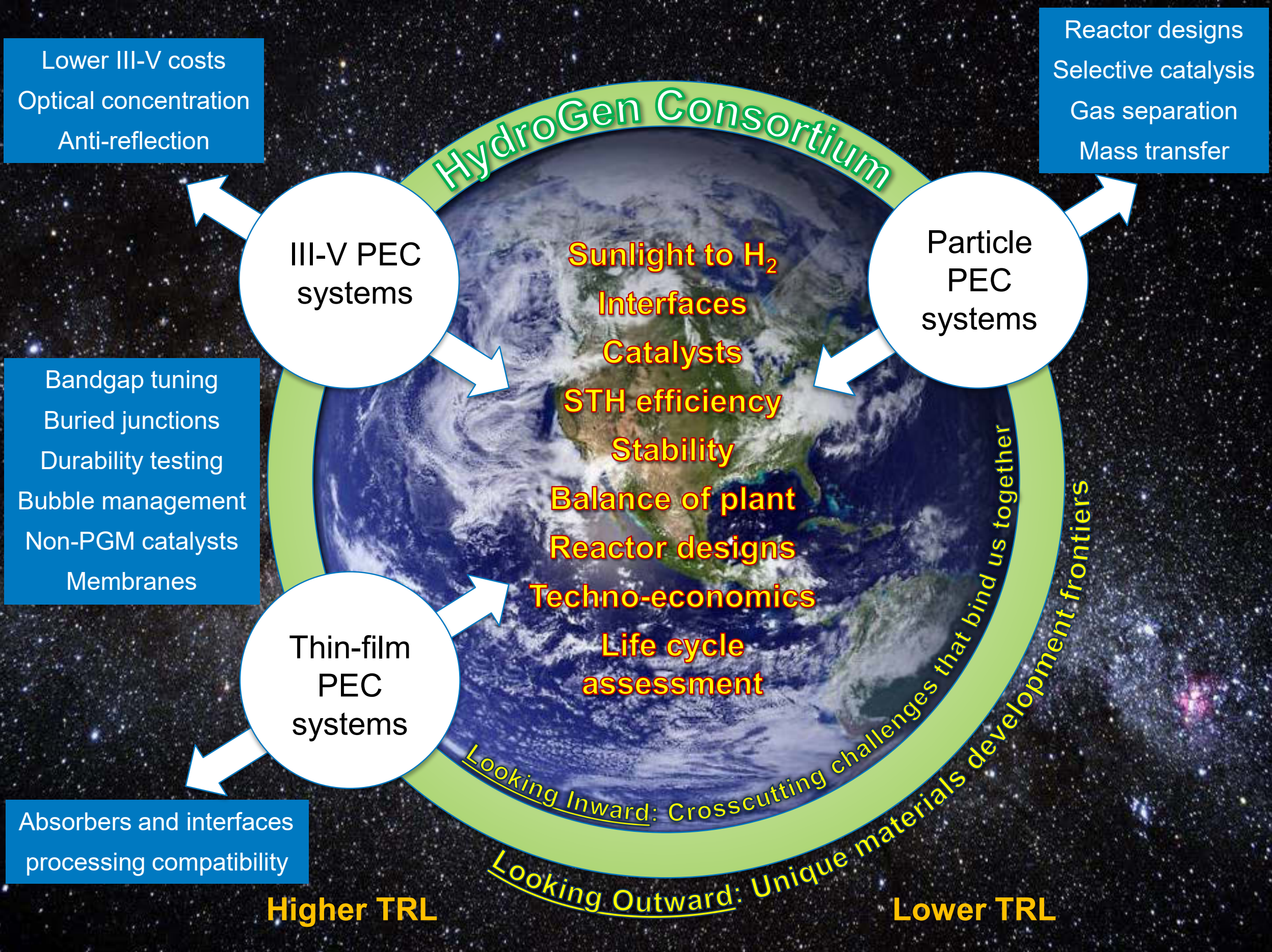




\section{Approach: Pathways to III-V Semiconductor Cost}

\section{Reductions}

\section{- Optical concentration}

- 10x-1000x uses less absorber

- Reuse substrate

Woodhouse et al. Report NREL/PR-6A20-60126

- Epitaxial lift-off (ELO)

Shermer et al., PSSa 202, 501-508 (2005)

- ELO with graphene interlayer

Kim et al., Nature 544, 340-343 (2017)

- Multilayer epitaxial assemblies

Kang et al., APL 102, 253902 (2013)

- Spalling

Shahrjerdi et al., APL 100, 053901 (2012)

- Laser lift-off

Hayes \& Clemens, MRS Comm. 5, 1-5 (2015).

\section{- Alternative substrate}

Woodhouse et al. Report NREL/PR-6A20-60126

$$
\text { - III-V on Si }
$$

Geisz \& Friedman, Semi. Sci. Tech. 17, 769-777 (2002)

- Metal foil

- Close-spaced vapor transport Kiriya et al., JAP 112, 123102 (2012)

- Ion beam assisted deposition Dutta et al., APL 105, 092104 (2014)

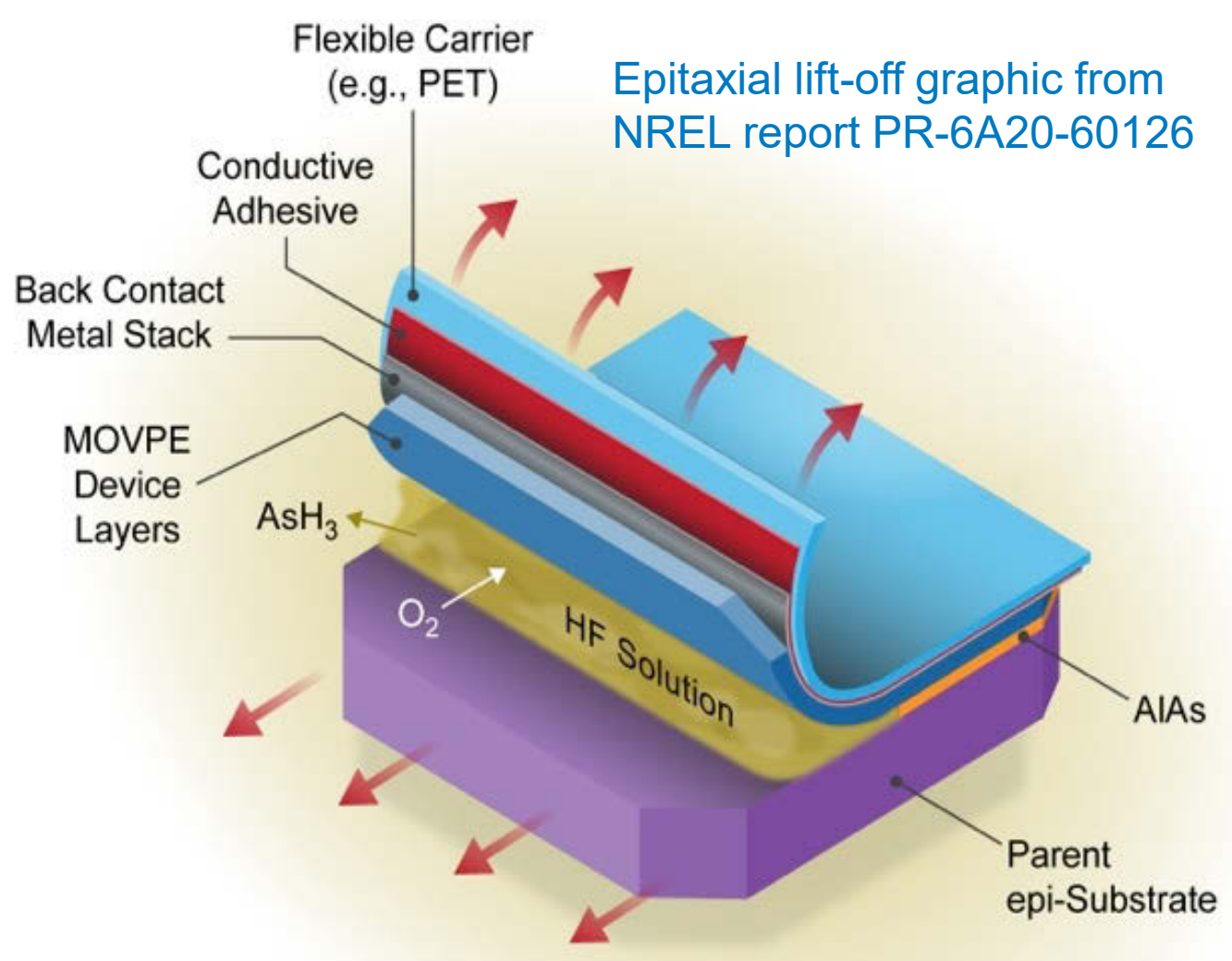

- Alternative precursors

- Close-spaced vapor transport Ritenour et al., ACS AMI 4, 69-73 (2012)

- Hydride vapor phase epitaxy Schulte et al., JAP 113, 174903 (2013)

This is a very active area of research that includes commercial cell manufacturers and funding support from ARPA-E. 


\section{Inverted Metamorphic Multijunction (IMM) Cells for}

\section{Unrivaled STH Efficiency}

IMM grown by organometallic vapor phase epitaxy (OMVPE)

Metamorphic: graded lattice constant interconnect, minimizing defects Inverted: top cell grown first, avoid lattice mismatch, can add back reflector

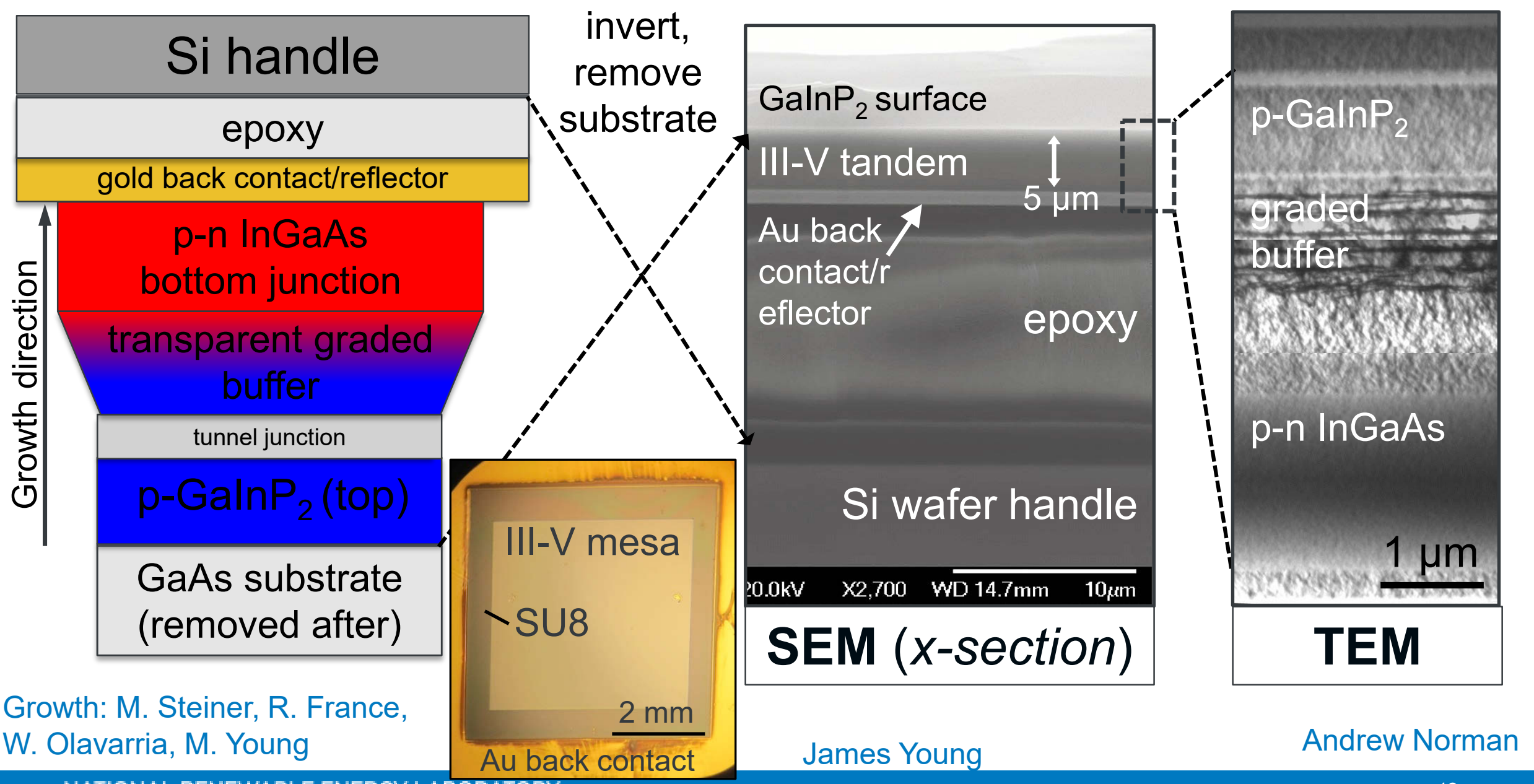




\section{Progress: World Record Efficiency and Benchmarking}

- Achieved world record STH efficiency for immersed PEC electrode with IMM

- Benchmarked outside with spectral correction factor

C. R. Osterwald, Sol. Cells. 18, 269-279 (1986).

- Follow method of reference cell calibration

- Perform calibration number correction for each junction

- Take the lower of the two values for reporting under reference spectrum

$I_{s c}^{0}=I_{s c}^{\text {meas }} \frac{1000 \mathrm{~W} \mathrm{~m}^{-2}}{E_{\text {meas }}} \times C N$,

$C N=\frac{\int_{300}^{4000} E_{R E F}(\lambda) S R^{R C}(\lambda) d \lambda \cdot \int_{300}^{4000} E_{I N C}(\lambda) d \lambda}{\int_{300}^{4000} E_{R E F}(\lambda) d \lambda \cdot \int_{300}^{4000} E_{I N C}(\lambda) S R^{R C}(\lambda) d \lambda}$.

"Direct solar-to-hydrogen conversion via inverted metamorphic multi-junction semiconductor architectures" James L. Young, Myles A. Steiner, Henning Döscher, Ryan M. France, John A. Turner, and Todd G. Deutsch, Nature Energy 2, 17028 (2017).
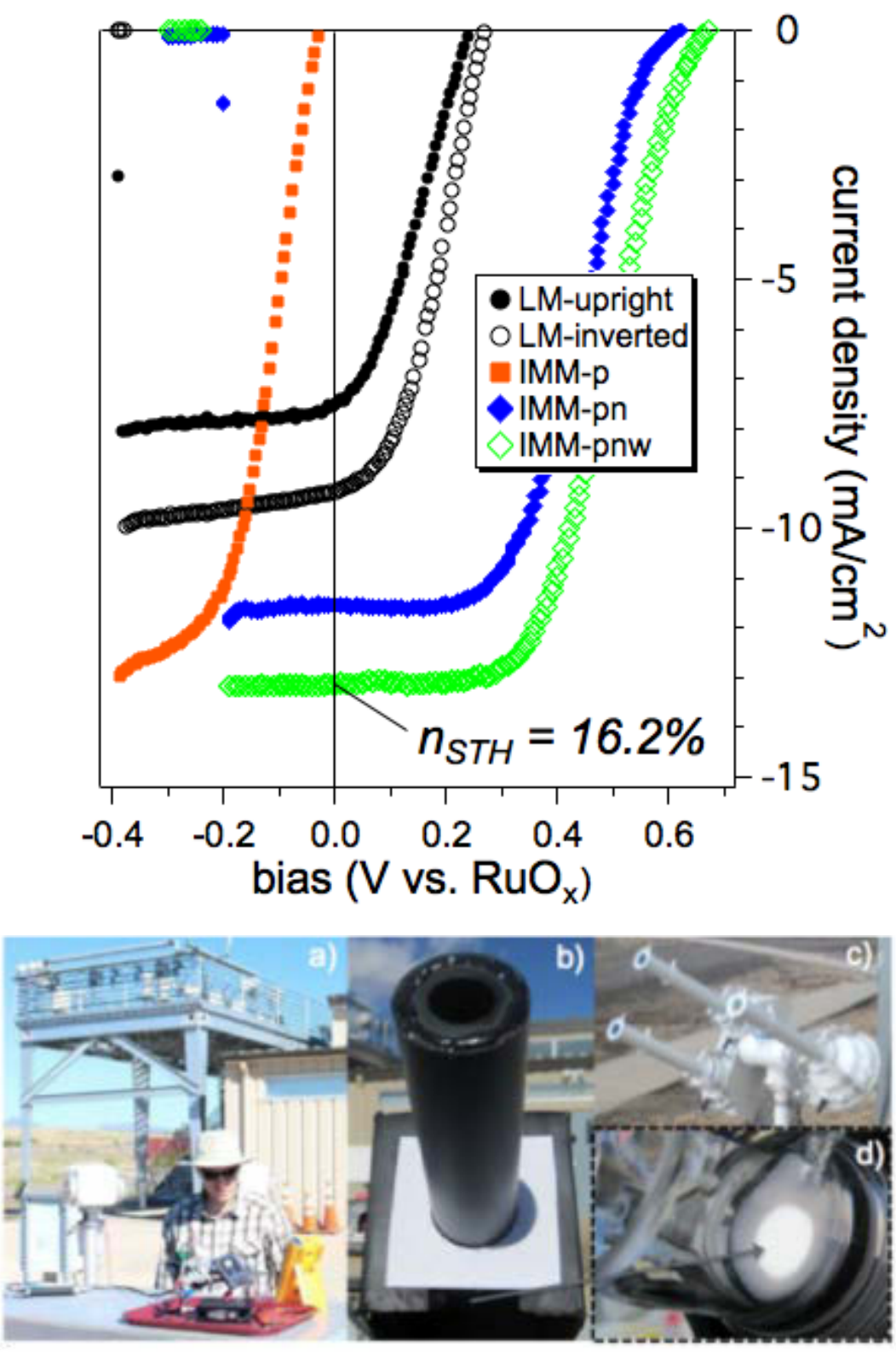


\section{Progress: Faradaic Efficiency and Photoreactor Testing}

- Mass-spectrometer based Faradaic efficiency system

- Custom built

- Continuous quantitative measurements

- Very low limit of detection (200 ppm $\mathrm{O}_{2}$ )

- Tracker-mounted photoreactor

- Long-term outdoor benchmarking

- Optical concentration (Fresnel lens)
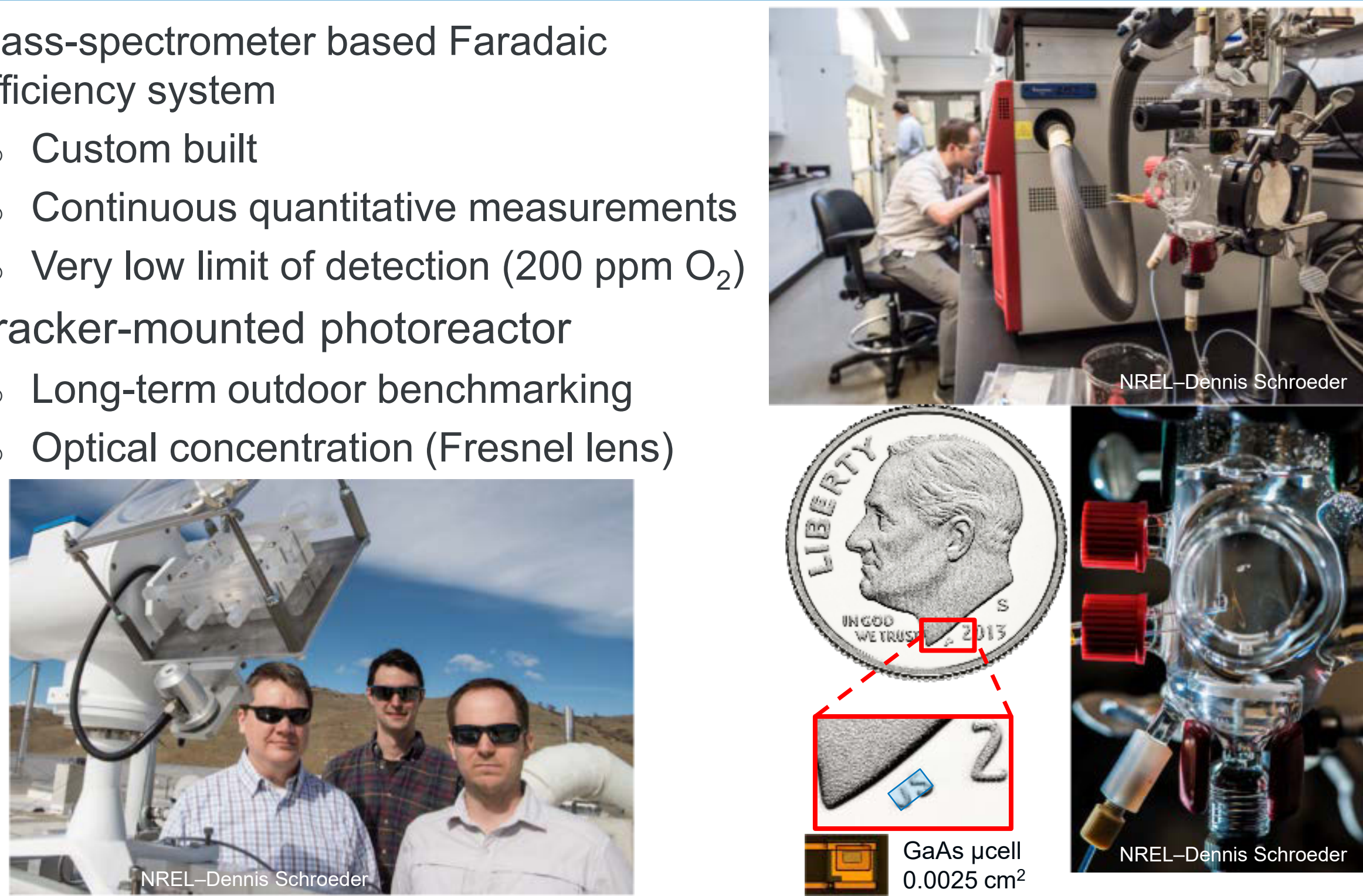

"Printed assemblies of GaAs photoelectrodes with decoupled optical and reactive interfaces for unassisted solar water splitting" Dongseok Kang, James L. Young, Haneol Lim, Walter E. Klein, Huandong Chen, Yuzhou Xi, Boju Gai, Todd G. Deutsch, and Jongseung Yoon, Nature Energy 2, 17043 (2017). 


\section{Progress: III-V Anti-reflection with USC}

- Refection reduces $\mathrm{GalnP}_{2}$ photocurrent, STH by $26 \%$

- Theoretical limit (1.8 eV band gap): $20.1 \mathrm{~mA} / \mathrm{cm}^{2}$, Reflection limit: $14.8 \mathrm{~mA} / \mathrm{cm}^{2}$

- Absorption of various nanopillar geometries modeled

- Chrome patterns applied by nanoimprint lithography

- $G a l n P_{2}$ etched by $\mathrm{BCl}_{3}$ reactive ion etching ( $\left.\mathrm{RIE}\right)$

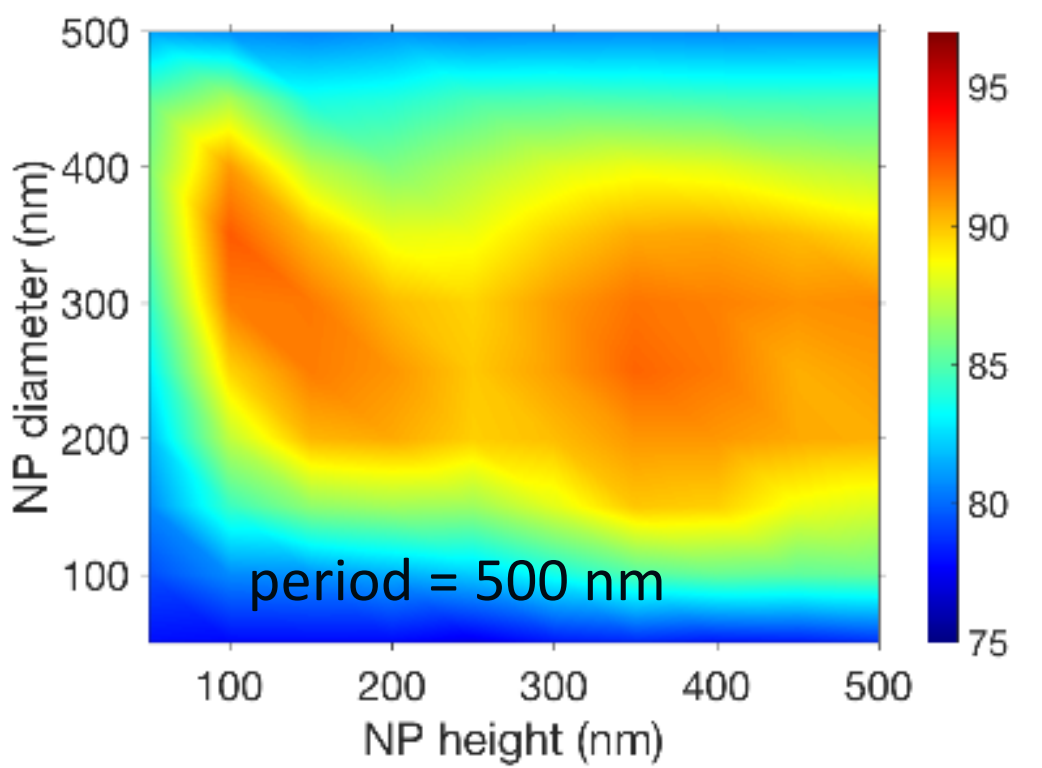

Haneol Lim of Prof. Jongseung Yoon lab (USC)
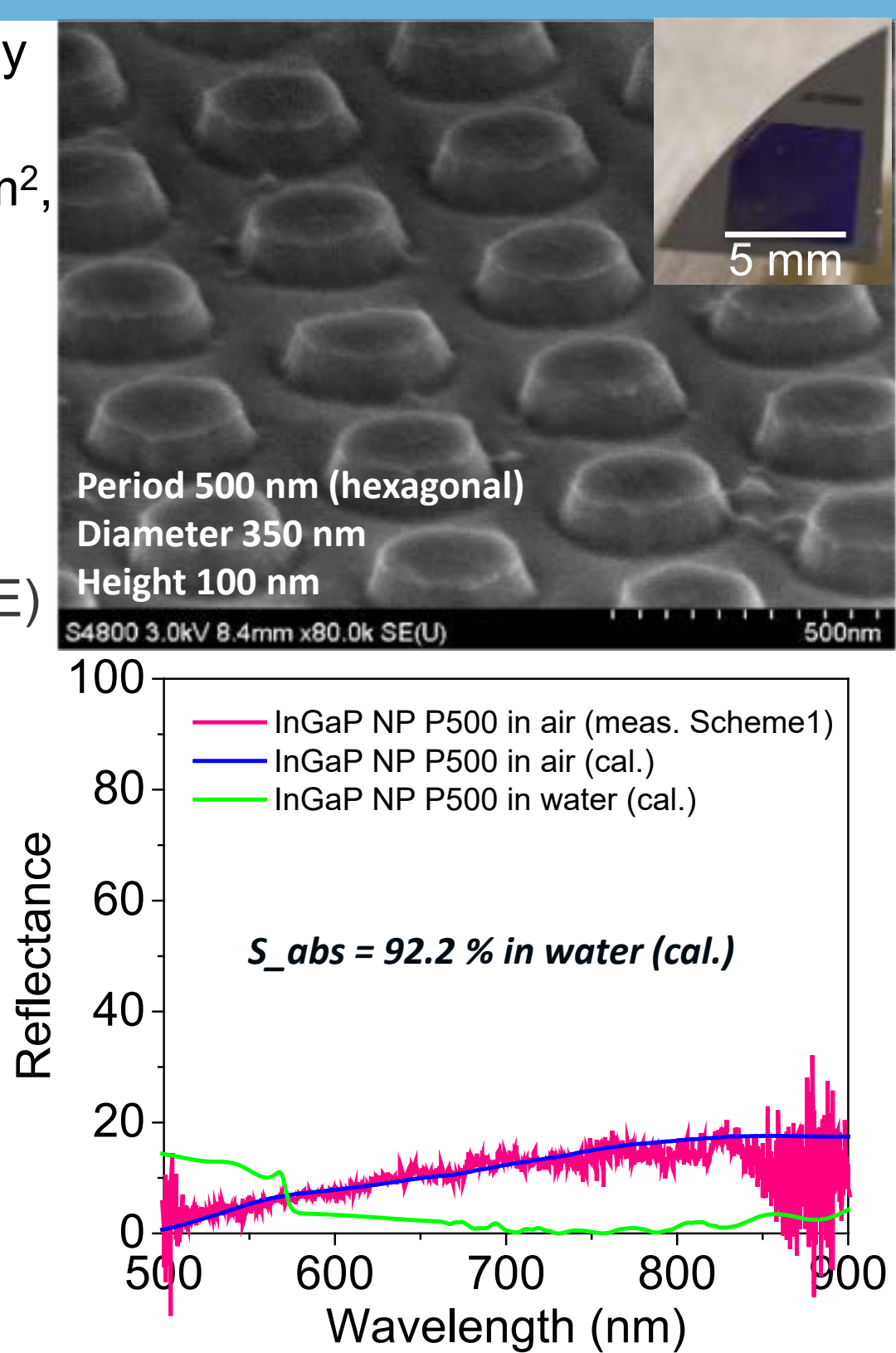


\section{Progress: Durability with Stanford; New Mounting}

Reuben Britto from Prof. Tom Jaramillo lab (Stanford)

- $\mathrm{MoS}_{2}$ protective coating on upright p-n GalnP 2

- Good stability $(100 \mathrm{~h})$

- Excellent catalytic properties

- Sputtered Mo layer attenuates light
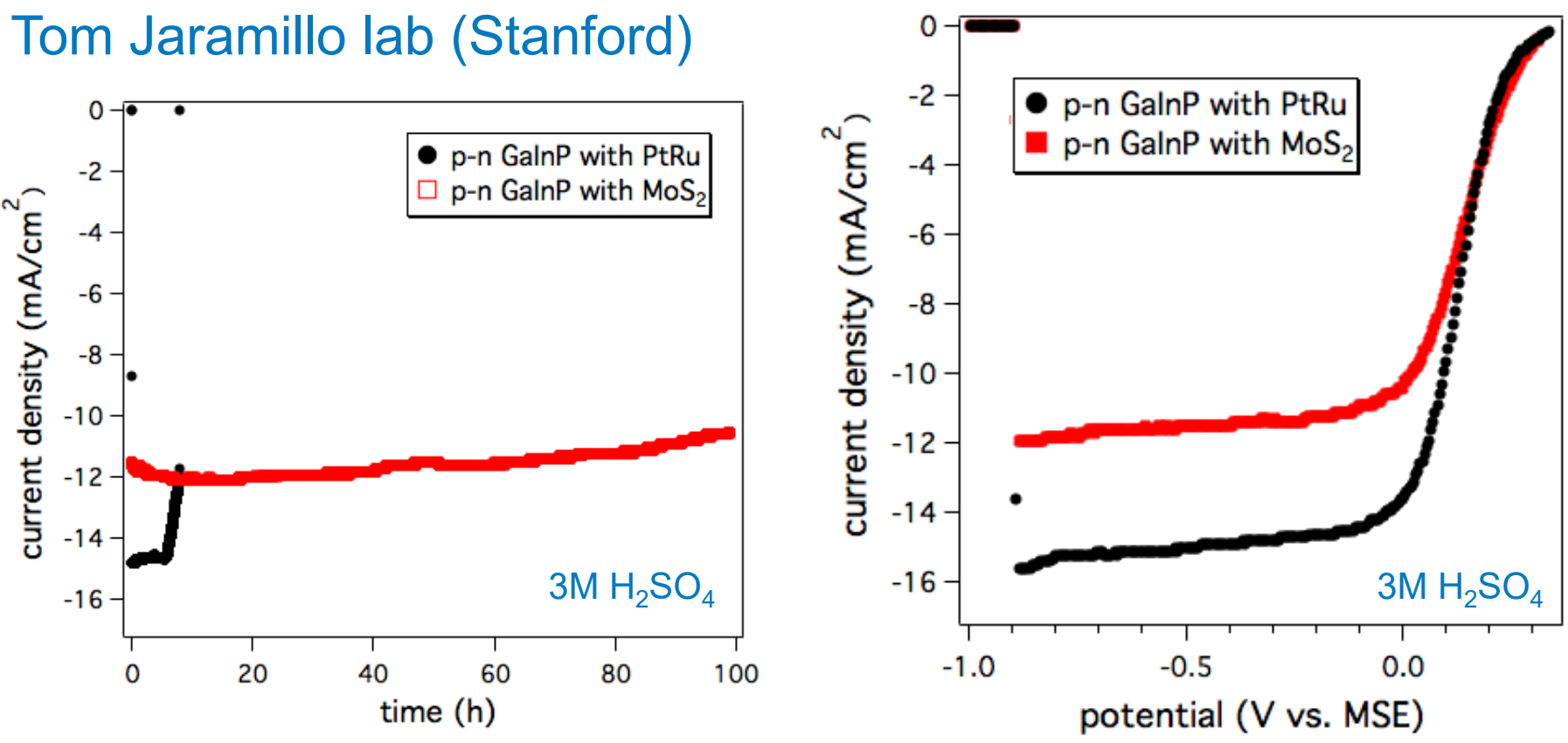

- New mounting procedure developed for IMM durability testing

- Modified compression cell

- Circular IMM mesa isolation

- Ultrasonically milled circular apertures in glass slides

- Double stick tape gasket

- Digital microscope for continuous monitoring

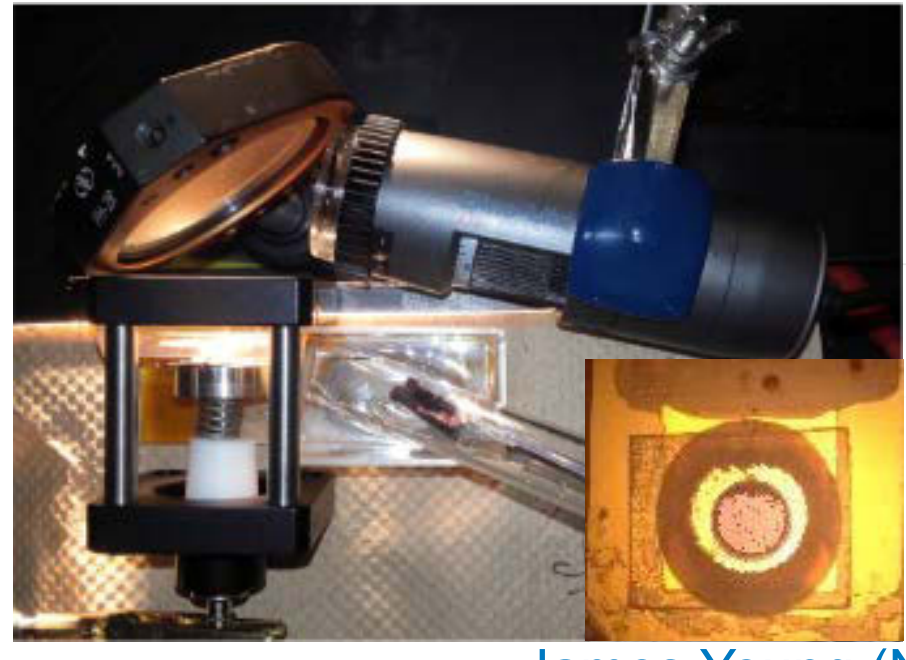

James Young (NREL)
Au back contact

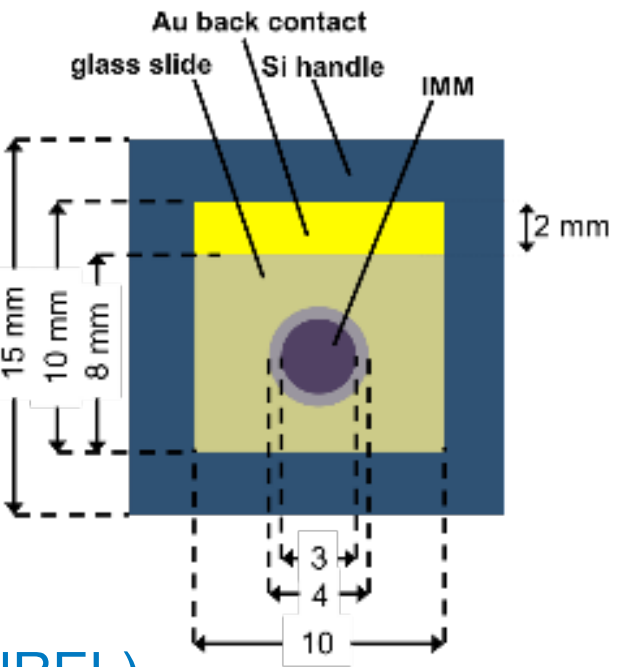




\section{Progress: Durability with JCAP}

- Working with JCAP North (LBNL) to apply a method they developed to encapsulate and immerse PEC electrodes

- Transparent epoxy infilled conductive, catalytic mesh Walczak...Sharp, Adv. Energy Mater. 2017, 1602791

- They achieved 7 days of stability

- Titanium mesh $70 \%$ optical transmission

- Tracked down more transmissive mesh

- Nickel mesh, 95\% optical transmission

- $32 \mu \mathrm{m}$ wide lines, $1.2 \mathrm{~mm}$ openings

NREL's role in collaboration:

Electrodeposition of Pt on Ni mesh Growth/processing III-V IMM cells Durability testing on solar tracker

LBNL's role in collaboration: Assembling mesh, III-V, epoxy, chassis Durability testing on solar tracker

LBNL: Karl Walczak, Jeff Beeman, Ian Sharp

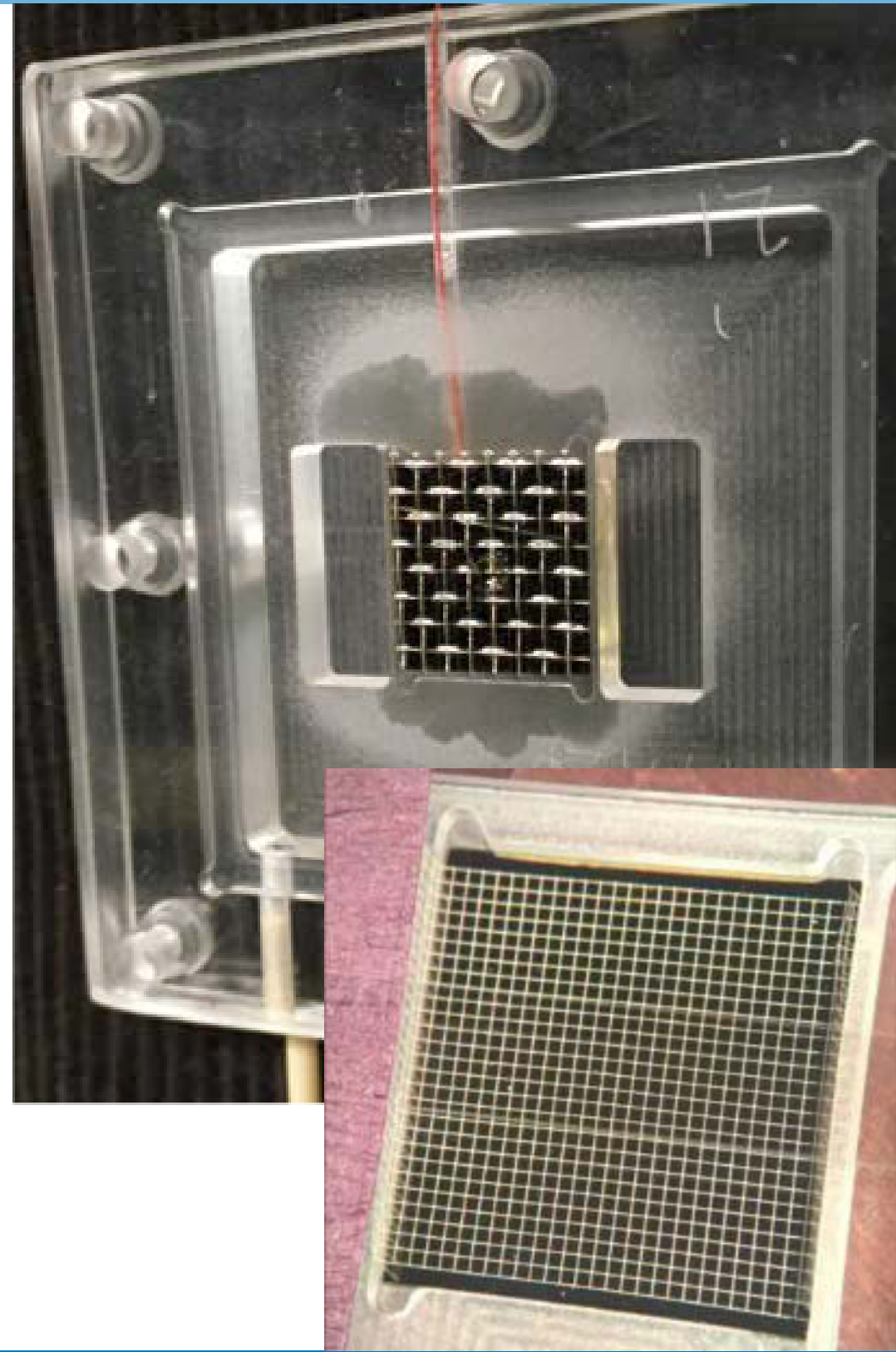




\section{Progress: UNLV Quaternary Materials}

- Working with surface validation partner to uncover reason for interesting durability behavior of GalnAsP

- After degradation, resting at open-circuit potential (OCP) restores (improves) original performance
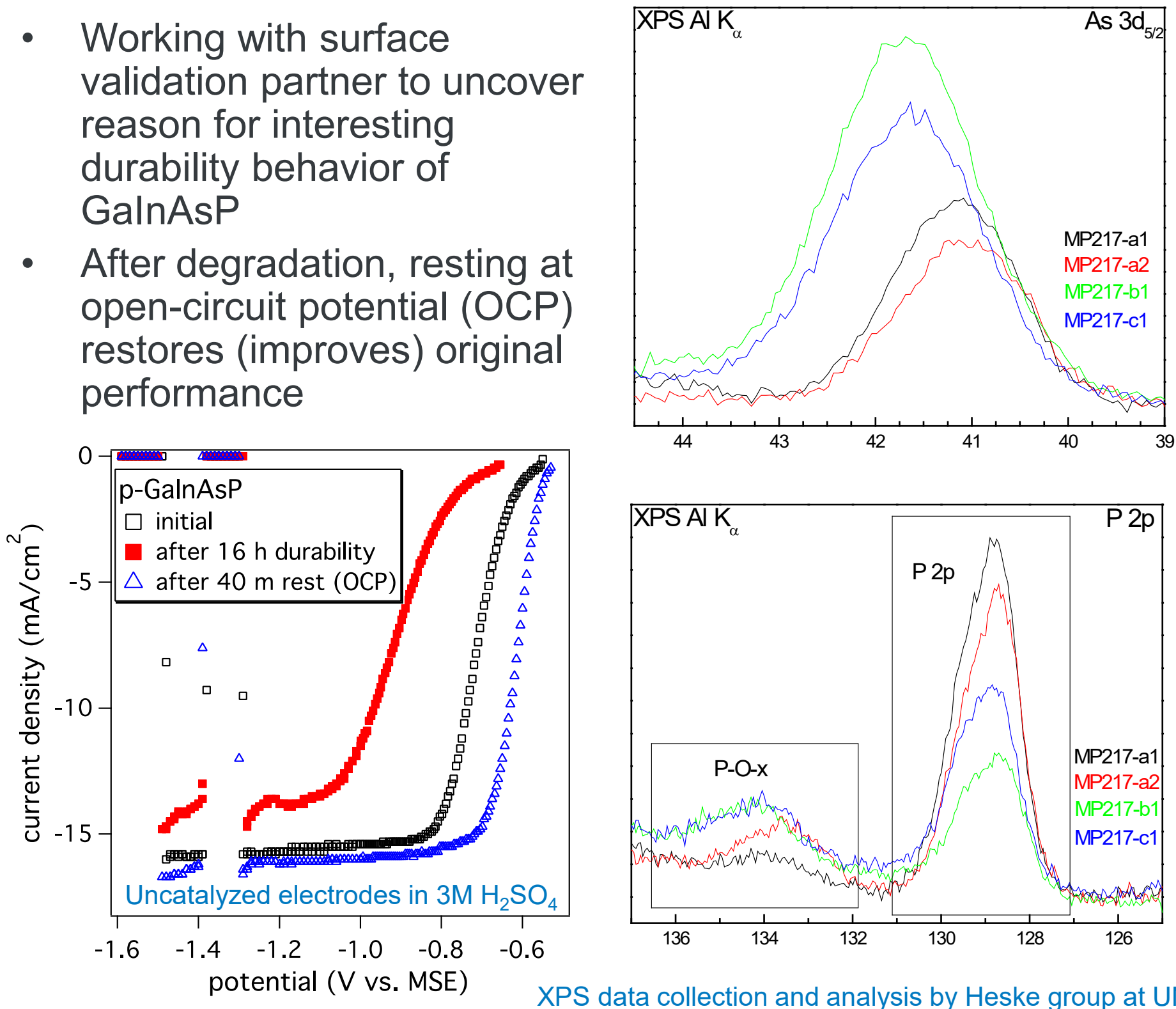

XPS data collection and analysis by Heske group at UNLV
GalnAsP samples sent to UNLV for analysis:

a1- as grown

a2- after ohmic contact

b1- degraded

c1- recovered

- Surface becomes Asenriched during durability testing and stays enriched after recovery

- Decrease in Ga and In at surface

- Durability testing leads to reduced ratio of P/POx

- Recovery reverses that trend and increases P/POx ratio, but not to initial value

- Confirms hypothesis that As can be beneficial in photocathodes 


\section{Responses to Previous Year Reviewers' Comments}

- "The project still has not addressed the photocorrosion aspect, which is critical to the progress."

- Response: We agree that photocorrosion remains the Achilles heel of all PEC approaches. While we've made incremental progress in passivating surfaces on test samples, stability is inadequate and potentially promising passivation approaches don't translate to full devices. This is an area that the entire field needs to confront. Specifically, diagnostic durability testing conditions have little relevance to the short-circuit condition of actual operating devices.

"The $16.3 \%$ efficiency is indeed impressive, and it shows the soundness of the approach. However, this world record should be considered along with durability. It is unclear whether stabilization of the $\mathrm{p}-\mathrm{GalnP}_{2}$ surface for 60 hours through $\mathrm{MoS}_{2}$ is a successful milestone or a promising future approach. Further, the prospects of improving the efficiency of the device are unclear. It seems that the team needs a better junction to do that; it is unclear whether there is a plan for this."

- Response: The IMMs are an ideal platform to demonstrate what PEC efficiencies can be achieved and to validate tandem STH iso-efficiency modeling. We are confident we can approach $20 \%$ STH efficiency just by reducing reflection of the current cells, and can surpass $20 \%$ STH by lowering the bandgap of the top junction. As mentioned above, the durability is still inadequate for the IMM cells, on the order of hours. $\mathrm{MoS}_{2}$ could be a promising future approach as well as the composite epoxy/mesh encapsulation. 


\section{Collaborations}

- Partners (extensive collaboration with all)

- Stanford University (PD119)

- Jaramillo group - Key partner in $\mathrm{MoS}_{2}$ for stabilization efforts

- McIntyre group - Impedance spectroscopy to map trap states in GalnP 2 samples we provided

- University of Southern California

- Yoon group - Benchmarking USC's GaAs $\mu$-cells, Nature Energy paper

- Anti-reflection modeling and experiments on $\mathrm{GalnP}_{2}$

- Joint Center for Artificial

Photosynthesis (North-LBNL)

- Ian Sharp, Karl Walczak - sample exchange, composite coatings, benchmarking cross-validation

○ University of Hawaii (PD116)

- Gaillard group - Partner on dual photoelectrode approach; sample exchange and validation
- University of Nevada Las Vegas

- Heske group - Partner in surface validation project

- Lawrence Livermore National Laboratory

- Ogitsu group - Partner in surface validation project

- University of Louisville

- Sunkara group - novel III-Vs $\left(\mathrm{GaAs}_{\mathrm{x}} \mathrm{Sb}_{1-\mathrm{x}}, \mathrm{GaSb}_{\mathrm{x}} \mathrm{P}_{1-\mathrm{x}}\right)$

- Joint characterizations/publications

- University of Toledo (PD118)

- Yan group - sample exchange, joint manuscript

- Colorado School of Mines

- Electron microscopy and XPS user facilities

- University of Colorado

- Colorado Naofabrication Laboratory user facility 


\section{Remaining Challenges and Barriers}

- Durability:

- More realistic real-world durability assessments - none of the reported impressive 100+ hours in biased three-electrode tests translate to true unbiased two-electrode configurations

- Buried junction eliminates requirement of contact with electrolyte to generate electric field - relaxes constraints on protective coating

- Efficiency:

- Push solar-to-hydrogen efficiency from $16 \%$ to beyond $20 \%$ for meeting ultimate DOE targets

- Semiconductor costs:

- Reduce synthesis costs by factor of 100 compared to current cost of smallbatch III-V materials

- System testing:

- Test promising photoreactor designs and components on solar tracker

- Window/body material, sealant/epoxy, membrane, counter electrode 


\section{Future Work: Photoreactor Demonstration}

FOA award deliverable: Incorporate most efficient and stable material in a photoreactor on a tracker and demonstrate 8 hours of continuous operation in sunlight with a cumulative production of at least 3 standard liters of $\mathrm{H}_{2}$
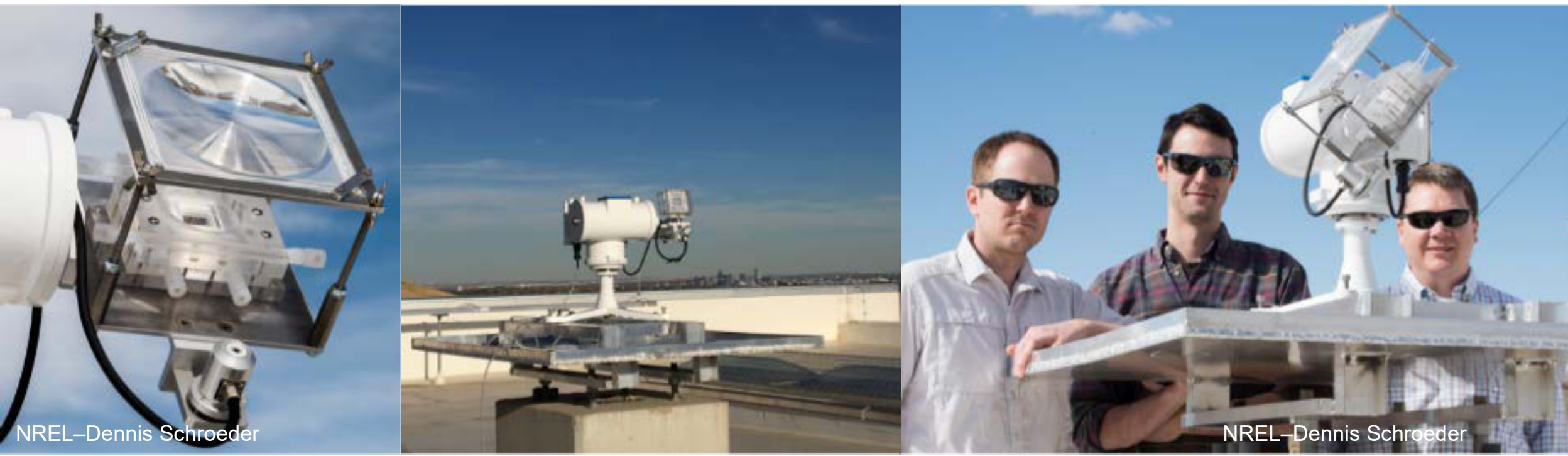

- To get 3 standard liters of $\mathrm{H}_{2}$ in 8 hours need

- $8 \mathrm{~cm}^{2}$ of IMM absorbers @ 15\% STH efficiency, 100 \% Faradaic efficiency

- Two or three photoreactors on solar tracker

- 10x optical concentration

- Reasonable durability

- Sunlight

$\mathrm{J}\left(\mathrm{mA} / \mathrm{cm}^{\wedge} 2\right)$ Area $\left(\mathrm{cm}^{\wedge} \mathbf{2}\right)$ Time $(\mathrm{min})$ Temp(K) Pressure(atm) Moles H2 Volume $(\mathrm{ml}) \mathrm{H} 2$ 125 $8 \quad 480$

273

1

0.149 3343 


\section{Future Work- Towards Economical Hydrogen}

In order to achieve the EERE plant-gate, untaxed cost targets of $\$ 1-2 / \mathrm{kg} \mathrm{H}_{2}\left(1 \mathrm{~kg} \mathrm{H}_{2}=1 \mathrm{gge}\right)$ requires a PEC system that uses $10 x$ concentration, has $25 \%$ solar-to-hydrogen (STH) efficiency, a semiconductor cost around $\$ 150 / \mathrm{m}^{2}$, and 10 years of stability. With suitable concentration $(>100 \mathrm{x})$, cost target can also be met with higher absorber costs $\left(\$ 805 / \mathrm{m}^{2}\right)$ and shorter (2 y) lifetime.

\section{- Efficiency}

- Validate $>15 \%$ STH efficiency on-sun at short circuit, $20 \%$ stretch goal

- Push efficiency by incorporating PV techniques (window layer, contact layer, ARC) and testing lower bandgap configurations that sacrifice voltage to achieve higher currents (efficiencies)

\section{- Durability}

- Continue evaluating surface protection approaches and investigate novel encapsulation concepts

- Demonstrate over 875 hours of durability on $15 \%$ efficient encapsulated IMM at short circuit

\section{- Semiconductor Cost}

- Test photoreactors with higher concentration to evaluate what levels are practically achievable under various configurations

- Obtain samples for PEC characterization from innovative III-V synthesis routes being developed by other DOE programs (SunShot, ARPA-E)

- Epitaxial lift-off, spalling, HVPE, CSVT

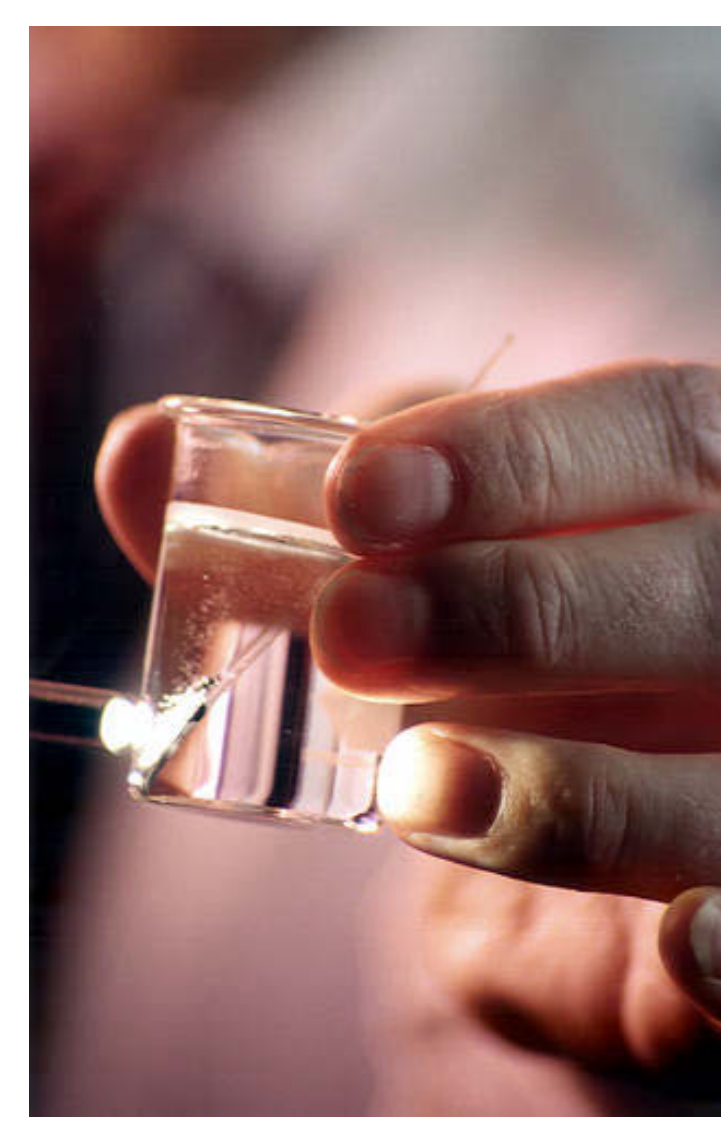

\section{- Photoreactor Prototyping}

- Test photoreactors with optical concentration and low or no electrolyte penetration depth for on-sun measurements on a solar tracker. 


\section{Project Summary}

\section{Relevance:}

\section{Approach:}

\section{Technical}

Accomplishments:

\section{Collaborations:}

\section{Proposed Future}

Work:
Spearheading research in high-efficiency materials in order to meet DOE metrics and objectives for solar-hydrogen generation

Focus on high-efficiency III-V crystalline semiconductor systems, an NREL core competency: investigation of new materials and configurations as well as stabilization of $\mathrm{GalnP}_{2}$ surface

Set new STH efficiency world record for immersed PEC cell, established protocol and standardized methods for efficiency benchmarking, built and validated a unique Faradaic efficiency measurement system capable of continuous measurements with low limit of detection, developed antireflective surface for III-Vs for enhanced efficiency with USC, extended durability with $\mathrm{MoS}_{2}$ surface treatment with Stanford, developed new sample mounting procedure for durability testing, improved composite encapsulation for extended durability with LBNL, made progress in understanding native durability of GalnAsP with surface validation partner (UNLV), designed and fabricated a photoreactor for long-term outdoor testing.

Several ongoing, active collaborations with synthesis, modeling, and characterization groups

Engineer more stable epitaxial capping layers, incorporate antireflective surfaces into tandem cells, extend IMM durability with $\mathrm{MoS}_{2}$ or composite coatings, demonstrate $3 \mathrm{~L}$ in $8 \mathrm{~h}$ on photoreactor 


\section{Technology Transfer Activities}

- Filed provisional patent on "PASSIVATING WINDOW AND CAPPING LAYER FOR PHOTOELECTROCHEMICAL CELLS." NREL filed U.S. a provisional patent application corresponding to NREL Record of Invention (ROI) No. 16-114 on August 16, 2016 at the United States Patent \& Trademark Office (USPTO) and has received Application No. 62/375,718.

- Filed a non-provisional patent on "Devices and Methods for Photoelectrochemical water splitting" March $23^{\text {rd }}, 2016$ based on our IMM for high efficiency work. United States Patent Application 20160281247. Awaiting examination. 


\section{Acknowledgements}

o James Young, Myles Steiner, Ellis Klein, Nathan Rodkey, John Turner - NREL (my group)

○ Henning Döscher - Philipps-Universität Marburg

o Huyen Dinh, Ryan France, Dan Friedman, Tom Gennett NREL

- Clemens Heske, Monika Blum, James Carter, Chase Aldridge, Lothar Weinhardt - UNLV (\& KIT)

- Tadashi Ogitsu - LLNL

o Jongsueng Yoon, Haneol Lim, Dongseok Kang - USC

- Ian Sharp, Karl Walczak, Jeff Beeman - LBNL

- Tom Jaramillo, Reuben Britto - Stanford

- Nicolas Gaillard, Alex DeAngelis - HNEI

- Yanfa Yan, Jie Ge, Yue Yu - U-Toledo 


\title{
ANREL
}

\section{Thank you}

\author{
NREL/PR-5900-68489
}

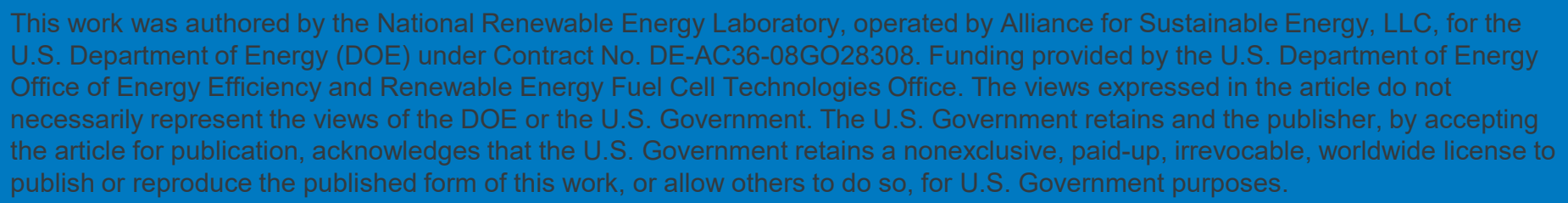




\section{ONREL}

Technical Back-Up Slides 
